\title{
EFFECT OF FINE PARTICULATE MATTER EXPOSURE ON TRIGGERING DEPRESSIVE-LIKE RESPONSE AND TOTAL BODY WEIGHT IN C57BL/6J MICE
}

\author{
Saima Saleem, Shabnam Hamid, Maria Iram, Abdul Basit Jilani*, Faiza Umbreen, Iram Zakria** \\ Army Medical College/National University of Medical Sciences (NUMS) Rawalpindi Pakistan, *Pakistan Institute of Engineering \& Applied Sciences, \\ Islamabad Pakistan, **HITEC Institute of Medical Sciences, Taxila/National University of Medical Sciences (NUMS) Pakistan
}

\begin{abstract}
Objective: To study the effect of fine particulate matter exposure in instigating depressive-like response and total body weight changes in C57BL/6J mice.

Study Design: Laboratory-based experimental study.

Place and Duration of Study: Anatomy Department, Army Medical College, Rawalpindi, in collaboration with the Military Hospital, Rawalpindi and the National Institute of Health (NIH), Islamabad, from Jun to Sep 2020.

Methodology: Thirty male and female C57BL/ 6 mice, 8 weeks of age, weighing $37 \pm 2$ gm were obtained from NIH, Islamabad. They were retained in separate cages in the animal house of NIH under standard laboratory conditions. The animals were divided into two groups, 15 mice in each group ( 8 males and 7 females) Group A was marked as control, received regular diet and water ad libitum. Group B (experimental group) received dynamic inhalation of $3 \mathrm{mg} / \mathrm{m}^{3}$ fine particles (soot) through air circulation for $6 \mathrm{~h} / \mathrm{d}$ for 12 weeks, in a plastic cabin measuring $2 \times 2 \times 2$ feet fitted with two small fans for evenly distribution of PM. The initial and final weight of animals was recorded, and a tail suspension test was performed to assess depression in form of immobility.

Result: The experimental group after exposure to fine particulate matter showed decreased activity and behavioural deficits with a $p$-value $<0.001$ and loss in total body weight as compared to the control group with a $p$-value $<0.001$.

Conclusion: Fine particulate matter has a significant effect on behaviour and cognition. It also causes a decrease in the total body weight of animals due to stress and agitation.
\end{abstract}

Keywords: Depressive behaviour, Fine particulate matter (FPM), Immobility, Stress, Tail suspension test (TST).

How to Cite This Article: Saleem S, Hamid S, Iram M, Jilani AB, Umbreen F, Zakria I. Effect of Fine Particulate Matter Exposure on Triggering Depressive-Like Response and Total Body Weight in C57bl/6j Mice. Pak Armed Forces Med J 2021; 71(6): 2114-2117. Doi: https://doi.org/10.51253/pafmj.v71i6.5809

This is an Open Access article distributed under the terms of the Creative Commons Attribution License (https://creativecommons.org/licenses/by-nc/4.0/), which permits unrestricted use, distribution, and reproduction in any medium provided the original work is properly cited.

\section{INTRODUCTION}

Air pollution is a major public concern that has adverse health and economic effects. Fine particulate matter containing many chemical components within these gradients, which can differ dynamically with time and space and with an aerodynamic diameter of $<10 \mu \mathrm{m}$, is often associated with air pollution in large cities. ${ }^{1}$ The presence of particulate matter is responsible for more damage to human health as compared to ground-level ozone. ${ }^{2-3}$ Particulate matter is either created directly by ignition or by automatic processes and indirectly by the condensation of aerosol precursor gases. ${ }^{4}$ Aerodynamic diameter is usually known as particulate matter (PM), ranging from coarse (between 2.5 and 10 $\mu \mathrm{m}$; PM10) to fine $(<2.5 \mu \mathrm{m}$; PM 2.5) to ultrafine $(<100$ $\mathrm{nm}$ or $0.1 \mu \mathrm{m}$ UFP). Ambient UFPs, which result mainly from ignition processes, include the burning of fossil fuels, has a primary source in the form of automobile emissions.5,6 Primary air pollutants can cause adverse

Correspondence: Dr Saima Saleem, House No. 1143 Main Road 01 Go15/1 Islamabad-Pakistan

Received: 08 Dec 2020; revision received: 06 Apr 2021; accepted: 09 Apr 2021 effects through a variety of mechanisms in the brain. Inflammatory mediators developed because of chronic pollutant-induced epithelial and endothelial injury in the respiratory tract and then released into the bloodstream can stimulate endothelium in the brain and cross the blood-brain barrier (BBB). PM exposure results in neurobehavioral issues, including the prevalence and progression of depression, Parkinson's disease and Alzheimer's disease. Oxidative stress and systemic inflammation are the main tools by which PM exposure poses a health risk. PM exposure is capable of activating pro-inflammatory pathways by inducing the release of inflammatory cytokines in the central nervous system (CNS), such as interleukin-1b (IL-1b), interleukin-6 (IL-6), antitumor necrosis factor-a (TNFa), interferon-c. ${ }^{7}$ According to the cytokine depression hypothesis, this can be accompanied by warning signs characteristic of despair, anorexia, fatigue, weight loss, and reduced activity. ${ }^{7}$

Capillaries present in the brain and parenchyma of Humans has been recognized as containing particulate matter. Various studies have shown that nanopar- 
ticles can decrease the viability of microvascular endothelial cells in the human brain, modify mitochondrial capacity, intensify oxidative stress, and decline protein expression of tight junctions, indicating that endothelial cells and blood-brain barrier can be disrupted by particulate matter. ${ }^{8}$ Systemic inflammation is attributed to the actions of strokes, neurodegenerative disorders, and sickness. The central nervous system and peripheral immune system interrelates with each other with the help of cytokines. The cellular character of innate immune cells in the brain, damage to the cells and modification of the ROS/cytokine system in the brain 7 are affected by inflammation.

Fine particulate matter is especially significant among different air contaminants for neurobehavioral outcomes because it can easily enter the brain because of its small size. People presenting with mental illnesses, including anxiety disorders, are at an elevated threat of suicide, which is among the projecting causes of death. Depressive illness has since become a significant threat to public health. Exposure to ambient air pollution imposes significant exacerbation of arrhythmia, diabetes, myocardial infarction and stroke. An association between ambient air pollution and mental disorders such as depression and suicide ${ }^{9}$ has been documented by recent epidemiological studies.

A severe depressive disorder which is characterized by an impaired frame of mind, loss of awareness, fatigue and tiredness is one of the most prominent mental disorders and the leading cause of disability in the whole world due to inflammatory processes and systemic and neuroinflammation plays a significant role in the development of major depressive disorders. ${ }^{10}$ Studies have focused on the histological effect of fine particulate matter on multiple organs for example lungs, heart, nasal mucosa, maternal exposure and some components of the brain. Despite considerable literature, there is still a need for studies, which should investigate the histomorphological changes in the brain because of the rapidly increasing rate of dispersion of air pollutants, especially in developing countries like Pakistan. Considering this we planned a study to observe the effects of particulate matter on total body weight change and depressive behaviour in the form of immobility.

\section{METHODOLOGY}

This laboratory-based experimental study was conducted at department of Anatomy, Army Medical College, Rawalpindi in collaboration with the National Institute of Health (NIH), Islamabad, from June to
September 2020, after getting approval from the Army Medical College, Rawalpindi, and the National University of Medical Sciences, Islamabad, Ethical Review Committee (ERC/ID/102). Non-probability convenience sampling technique was used.

Inclusion Criteria: Thirty male and female C57BL/ 6 mice, 8 weeks of age, weighing $37 \pm 2$ grams were included in the study.

Exclusion Criteria: Mice with any obvious injury and disease were excluded.

The animals were procured from NIH, Islamabad. They were kept in separate cages in animal house of $\mathrm{NIH}$ under typical laboratory conditions with temperature $22 \pm 2^{\circ} \mathrm{C}$ and 12 -hour day/night cycle. The animals were fed on standard laboratory rat chow and water ad libitum. The animals have divided into two groups, with 15 mice in each group (8 males and 7 females). Group A (control group) mice in this group served as control. They received a standard diet and water ad Libitum. Group B (experimental group) received dynamic inhalation of $3 \mathrm{mg} / \mathrm{m}^{3}$ fine particles through air circulation for $6 \mathrm{~h} / \mathrm{d}$ for 12 weeks. ${ }^{11}$ The mice were placed in a plastic cabin measuring $2 \times 2 \times 2$ feet fitted with two small fans opposite each other in NIH Islamabad. Air circulation was maintained by a fan running at moderate speed. The particulate matter was evenly dispersed in the cabin through fan. ${ }^{12}$

Tail Suspension test: After 12 weeks of exposure, before sacrifice, in order to study the level of stress and depression due to exposure to particulate matter the mice were suspended by the tail with the help of tape about $50 \mathrm{~cm}$ from the ground as shown in Figure- 1 . During a test cycle of $6 \mathrm{~min}$, the duration during which mice stayed immobile was quantified. The mice were labelled immobile when they hang down inactively and does not struggle and move their body, except for those movements which are related to breathing. ${ }^{13,14}$

Bodyweight Change: Initial and final weights of animals were recorded using Triple beam balance. Bodyweight change was extracted by calculating the difference between them.

"Weight change = final weight- initial weight"

Data were evaluated by using Statistical Package for the social sciences (SPSS) version 23. Quantitative parameters e.g. body weight change and immobility in seconds were expressed as mean $\pm \mathrm{SD}$. A significant difference was determined by using an independent sample t-test. The $p$-value of $\leq 0.05$ was considered significant. 


\section{RESULTS}

Fifteen out of 30 mice with an average weight of $37 \pm 2$ gms were given dynamic inhalation of $3 \mathrm{mg} / \mathrm{m}^{3}$ fine particles through air circulation for $6 \mathrm{~h} / \mathrm{d}$ for 12 weeks. The mice were placed in a plastic cabin measuring $2 \times 2 \times 2$ feet fitted with two small fans opposite each other in NIH Islamabad. Air circulation was maintained by fans running at moderate speed. The particulate matter was evenly dispersed in the cabin through fans. Till the end of the experiment, all the animals remained alive. Both groups were subjected to a tail suspension test to evaluate Depressive-like responses. The mice belonging to control group A were active and healthy and struggled for escape during TST (Figure).

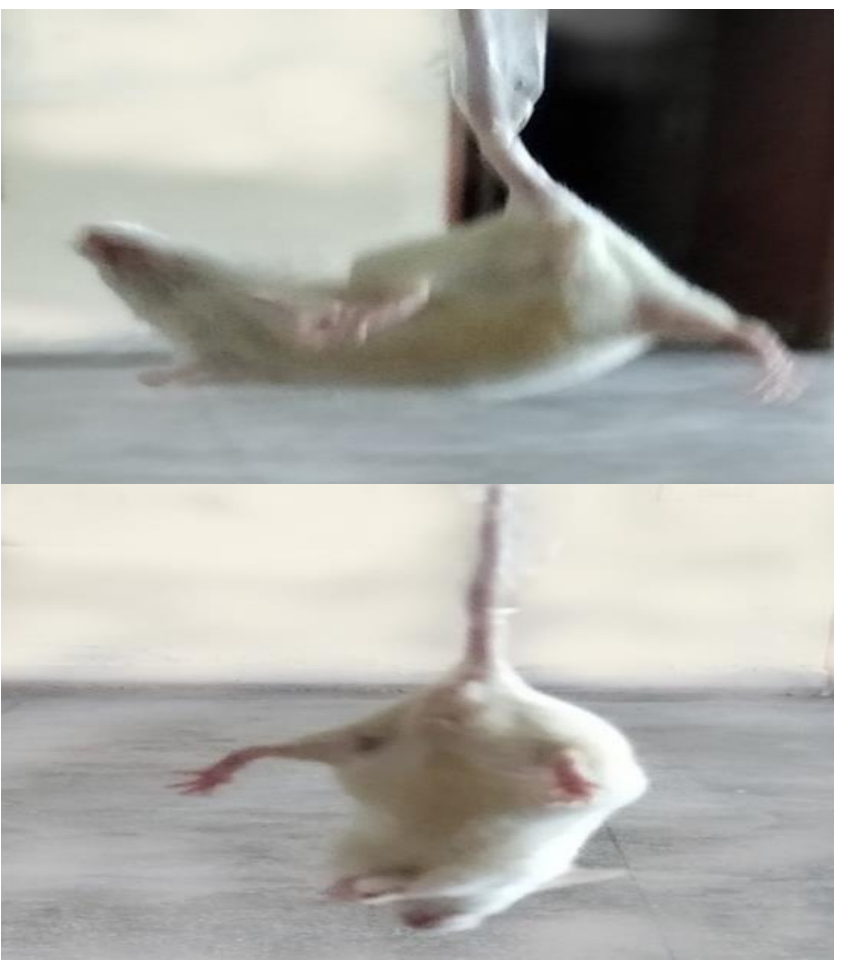

Figure: (a) Control group mouse struggling during TST. (b): Experimental group mouse with ceased body and limb movements.

The immobility time calculated for group A was mean $43.00 \pm 9.60 \mathrm{sec}$. whereas in experimental group $B$ the mice remained inactive and did not struggle for a period of $204 \pm 43 \mathrm{sec}$. Depressogenic-like effects of PM exposure were determined between group A and B by independent sample t-test $(p<0.001)$ which was significant, the initial and final weight of animals was recorded in grams by triple beam balance and weight change was calculated at the time of sacrifice. In control group A, the mean weight change was $2.00 \pm 0.02$ gm which is representing natural weight gain. While in experimental group $B$ the mean weight change was
$3.30 \pm 1.04 \mathrm{gm}$, representing weight loss due to $\mathrm{PM}$ exposure Intergroup comparison between $\mathrm{A}$ and $\mathrm{B}$ was a significant result ( $p$-value $<0.001)$ (Table).

Table: Comparison of mean values of quantitative parameters between control group A \& experimental group B.

\begin{tabular}{l|c|c|c}
\hline \multirow{2}{*}{ Parameters } & \multicolumn{2}{|c|}{ Mean \pm SD } & $\begin{array}{c}p \text { - } \\
\text { value }\end{array}$ \\
\cline { 2 - 3 } & Group A & Group B & $<0.001$ \\
\hline Weight change in grams & $2 \pm 0.02$ & $3.30 \pm 1.04$ & $<0.001$ \\
\hline Immobility in seconds & $43 \pm 9.60$ & $204 \pm 43$ & $<0.001$ \\
\hline
\end{tabular}

\section{DISCUSSION}

The study was carried out to estimate the triggering effect of long-term exposure to particulate matter on depressive-like behaviour in mice, primarily due to inflammation and oxidative stress. Oxidative stress occurs owing to deficiency of anti-reverse antioxidant system in the course of extreme free radical production, accompanied by accumulation of reactive nitrogen species (RNS) and reactive oxygen species (ROS). Oxidative stress has been recognized as a contributing factor in the process of ageing and neurodegenerative diseases like Alzheimer's. Excessive accumulation of ROS in the antioxidant system may cause disorders. Due to exposure to fine particulate matter, there is oxidative stress and damage to neurons because the brain has high lipid content, more energy requirements and feeble antioxidant capacity. ${ }^{15}$ Usually the toxicity of particulate matter depends upon the size, composition and concentration of the particles. ${ }^{16}$ Particulate matter binds itself to various substances including heavy metals, hydrocarbons, viruses and other toxic substances because of its surface area and in turn, leads to the generation of reactive oxygen species and inflammatory cytokines. The fine particulate matter along with various gases as air pollutants are potentially harmful to neuro physiological development especially in children. ${ }^{17}$

One of the parameters to assess brain activity and neurophysiological development is to check the behavioural changes. Therefore, in this study, the mice were subjected to a tail suspension test for 6 hours and the level of immobility was calculated and compared with control after giving PM exposure of $80 \mu \mathrm{g} / \mathrm{m}^{3}$ which is similar to the study conducted by 13 in which two groups of mice were exposed with PM concentration of 54,73 and $77 \mathrm{ug} / \mathrm{m}^{3}$ for a period of 3 months. In this study, animals showed decreased immobility and increased proinflammatory cytokines with $p<0.05$. In another study conducted by 5 , hyperoxia during treatment of prematurity and PM exposure both were used in C57BL/6J mice, as both of these factors are linked 
to various adverse neurodevelopmental outcomes. The particle diameter was ultrafine and with a concentration of $48 \mathrm{ug} / \mathrm{m}^{3}$. The study concluded that both hyperoxia and PM exposure affect learning and behaviour across many species including humans with $p \leq 0.05$.

The effect of weight was also calculated in this study. There was a significant decline in the weight of group B as compared to group A with a $p$-value $<0.05$. The decrease in weight is most probably due to stress and agitation. This study is similar to a study in which there is a decrease in the weight of animals after exposure to traffic-related pollution. ${ }^{18}$. The dose of PM used in this research was $342 \mu \mathrm{g} / \mathrm{m}^{3}$ and it displayed significant results with $p<0.05$ and showed a positive correlation between locomotor activity and weight loss. In another study conducted by giving exposure to mice with FPM long with gases1 showed a significant decrease in the weight of the body with $p<0.05$.

\section{CONCLUSION}

Fine particulate matter has a significant effect on behaviour and cognition. It also causes a decrease in the total body weight of animals due to stress and agitation.

\section{Conflict of Interest: None.}

\section{Disclosure}

Authors are extremely obliged to the National University of Medical Sciences, Islamabad for providing funds for our project.

\section{Authors' Contribution}

SS: Direct contribution, SH: Contribution in conception, MI: Helped in analysis, ABJ: Design and analysis, FU \& IZ: Interpretation of data.

\section{REFERENCES}

1. Ku T, Ji X, Zhang Y, Li G, Sang N. PM2. 5, SO2 and NO2 coexposure impairs neurobehavior and induces mitochondrial injuries in the mouse brain. Chemosh 2016; 163(1): 27-34.

2. Kim K-H, Kabir E, Kabir S. A review on the human health impact of airborne particulate matter. Environ Int 2015; 74(1): 136-43.

3. Brauer M, Amann M, Burnett RT, Cohen A, Dentener F, Ezzati $\mathrm{M}$, et al. Exposure assessment for estimation of the global burden of disease attributable to outdoor air pollution. Environ Sci Technol 2012; 46(2): 652-660.

4. Lee CJ, Martin RV, Henze DK, Brauer M, Cohen A. Response of global particulate-matter-related mortality to changes in local precursor emissions. Environ Sci Technol 2015; 49(7): 4335-4344.
5. Morris-Schaffer K, Merrill A, Jew K, Wong C, Conrad K, Harvey $\mathrm{K}$, et al. Effects of neonatal inhalation exposure to ultrafine carbon particles on pathology and behavioural outcomes in C57BL/6J mice. Part Fibre Tox 2019; 16(1): 10-15.

6. Harris MH, Gold DR, Rifas-Shiman SL, Melly SJ, Zanobetti A, Coull BA, et al. Prenatal and childhood traffic-related air pollution exposure and childhood executive function and behaviour. Neurotoxicol Teratol 2016; 57(1): 60-70.

7. Block ML, Calderón-Garcidueñas L. Air pollution: mechanisms of neuroinflammation and CNS disease. Trends Neurosci 2009; 32(9): 506-516.

8. Chen L, Yokel RA, Hennig B, Toborek M. Manufactured aluminium oxide nanoparticles decrease expression of tight junction proteins in brain vasculature. J Neuroimmune Pharmacol 2008; 3(4): 286-295.

9. Cho J, Choi YJ, Suh M, Sohn J, Kim H, Cho S-K, et al. Air pollution as a risk factor for a depressive episode in patients with cardiovascular disease, diabetes mellitus, or asthma. J Affect Disord 2014; 157(1): 45-51.

10. Kim K-N, Lim Y-H, Bae HJ, Kim M, Jung K, Hong Y-C. Longterm fine particulate matter exposure and major depressive disorder in a community-based urban cohort. Environ Health Perspect 2016; 124(10): 1547-1553.

11. Onoda A, Takeda K, Umezawa M. Dose-dependent induction of astrocyte activation and reactive astrogliosis in mouse brain following maternal exposure to carbon black nanoparticle. Part Fibre Toxicol 2017; 14(1): 4-8.

12. Li D, Zhang R, Cui L, Chu C, Zhang H, Sun H, et al. Multiple organ injury in male C57BL/6J mice exposed to ambient particulate matter in a real-ambient PM exposure system in Shijiazhuang, China. Environ Pollut 2019; 248(2): 874-887.

13. Liu X, Qian X, Xing J, Wang J, Sun $Y$, Wang QG, et al. Particulate matter triggers depressive-like response associated with modulation of inflammatory cytokine homeostasis and brain-derived neurotrophic factor signalling pathway in mice. Toxicol Sci 2018; 164(1): 278-288.

14. Wang Z, Gu J, Wang X, Xie K, Luan Q, Wan N, et al. Antidepressant-like activity of resveratrol treatment in the forced swim test and tail suspension test in mice: the HPA axis, BDNF expression and phosphorylation of ERK. Pharmacol Biochem Behav 2013; 112(2): 104-110.

15. Zhu X, Ji X, Shou Y, Huang Y, Hu Y, Wang H. Recent advances in understanding the mechanisms of PM2. 5-mediated neurodegenerative diseases. Toxicol Lett 2020; 329(1): 31-37.

16. Wang G, Jiang R, Zhao Z, Song W. Effects of ozone and fine particulate matter (PM2. 5) on rat system inflammation and cardiac function. Toxicol Lett 2013; 217(1): 23-33.

17. Suades-González E, Gascon M, Guxens M, Sunyer J. Air pollution and neuropsychological development: a review of the latest evidence. Endocrinol 2015; 156(10): 3473-3482.

18. Woodward NC, Pakbin P, Saffari A, Shirmohammadi F, Haghani A, Sioutas C, et al. Traffic-related air pollution impact on mouse brain accelerates myelin and neuritic ageing changes with specificity for CA1 neurons. Neurobiol Aging 2017; 53(1): 48-58. 